\title{
Controlling information flow in online information seeking: The moderating effects of utilitarian and hedonic consumers
}

\author{
Ling-Ling $\mathrm{Wu}^{\mathrm{a}}{ }^{\mathrm{a}}$, Yi-Ting Wang ${ }^{\mathrm{a}, *}$, Chin-Hsiu Wei ${ }^{\mathrm{a}}$, Ming-Yih Yeh ${ }^{\mathrm{b}}$ \\ a National Taiwan University, Taipei, Taiwan \\ ${ }^{\mathrm{b}}$ National Taiwan University of Science and Technology, Taipei, Taiwan
}

\section{A R T I C L E I N F O}

\section{Article history:}

Received 13 April 2015

Received in revised form 9 September 2015

Accepted 9 September 2015

Available online 30 September 2015

\section{Keywords:}

Information control

Shopping purpose

Involvement

Product attitude

Website satisfaction

\begin{abstract}
A B S T R A C T
Information control has been deemed one of the most prominent features of the Internet for online consumers searching product information. This study examined how information control affects the online information seeking processes of consumers and how the effects are moderated by shopping purposes (utilitarian vs. hedonic). This study recruited 292 respondents to participate in our experiment. The empirical results reveal that information control significantly increases consumer involvement in information seeking, enhances attitudes toward products, and elevates the degree of satisfaction toward commercial websites. Furthermore, the effects of information control on consumer involvement and product attitudes are moderated by their shopping purposes. The results support most of the proposed hypotheses, suggesting that information control works more effectively for utilitarian consumers than for hedonic consumers. The findings of this study offer online practitioners useful recommendations regarding personalization strategies of website design.
\end{abstract}

(c) 2015 Elsevier B.V. All rights reserved.

\section{Introduction}

Electronic commerce (e-commerce), particularly the businessto-consumer types such as Alibaba, has grown rapidly in recent years. Online stores attract consumers to shop because of characteristics unique to the Internet, such as easier price comparisons, wider selections, a higher level of convenience, and greater access to information compared with brick-and-mortar stores (Jarvenpaa and Todd 1996, Peterson et al. 1997). However, these characteristics pose two challenges to online retailers: low switch cost, which refers to consumers' effortlessly comparing prices from different providers and quickly switching to other online stores; and information overload, which overwhelms online consumers and complicates their information seeking and decision making (Hwang and Lin 1999). Thus, it is strategically crucial for online retailers to offer consumers effective assistance in searching information and making purchase decisions efficiently.

One of the most prominent features of the Internet is information control, which refers to the level of regulating the content, display order, and display time of information online (Ariely 2000). Under a high information control condition, consumers can actively manage the information seeking process and freely choose

* Corresponding author at: 4F., No. 118, Xizang Rd., Zhongzheng Dist., Taipei City 100, Taiwan. Tel.: +886 910012170; fax: +8862 33661192 .

E-mail address: d99725005@ntu.edu.tw (Y.-T. Wang). information content, display order, and reading time according to their preferences (Liu and Shrum 2002). For instance, consumers can use keywords in search engines and retrieve and read the relevant information that they query. By contrast, under the condition of low control, consumers are passively fed information provided by sellers. For example, pop-up ads are a typical example of low information control, under which the content, order, and time for consumers to read are predetermined. As previous studies have shown, information control facilitates the process of prepurchase information seeking and the purchase decisions of online consumers, by enhancing cognitive involvement (Jiang et al. 2010), attitudes toward websites (Chung and Ahn 2007, Hwang and McMillan 2002, Teo et al. 2003), confidence in judgments (Ariely 2000), intention to use a self-service technology (Collier and Sherrell 2010), and trust in mobile commerce (Lee 2005).

Although information control generally has positive effects, recent studies have demonstrated that such effects are not the same for all consumers (Sicilia et al. 2005, Wu and Lin 2006, 2012). Increasingly more researchers have advocated the contingency view of information control, which argues that the effects of information control depend on contingent conditions such as need for cognition (Sicilia et al. 2005), expertise (Wu and Lin 2006), and motivation (Wu and Lin 2012). Because information control is a prominent feature of the Internet, it is worthwhile to determine how user factors serve as critical contingent conditions 
for the effects of information control. Shopping purposes affect many aspects of online consumers behavior such as search intention (To et al. 2007), decision making (Dhar and Wertenbroch 2000), preference toward online retailers (Overby and Lee 2006), satisfaction with retailers (Jones et al. 2006), and intention to repurchase (Kim et al. 2012). Therefore, this study aims to investigate the moderating effects of shopping purposes on the effects of information control.

Similar to consumers in brick-and-mortar stores, online consumers may also have two shopping purposes: utilitarian or hedonic. Utilitarian purpose is described as a mission that is critical, rational, decision-effective, and goal-oriented (Batra and Ahtola 1991, Hirschman and Holbrook 1982, Wolfinbarger and Gilly 2001). Utilitarian consumers shop because of a specific goal or task, and the benefits of shopping depend on whether the goal is achieved or not, or whether the task is completed in efficiently (Babin et al. 1994, Batra and Ahtola 1991). Therefore, they primarily adopt a directed search behavior that is deliberate and mainly focused on the information related to the goal (Hoffman and Novak 1996, Janiszewski 1998, Novak et al. 2003). By contrast, hedonic purpose is defined as shopping for amusement, enjoyment, fantasy, novelty, variety, surprise, awakening, or sensuality (Hirschman and Holbrook 1982). In contrast to utilitarian consumers, the benefits of hedonic consumers are not related to achieving the physical objective or completing the task. By definition, hedonic consumers enjoy shopping and acquire experiential and emotional benefits during the process (Babin et al. 1994). In contrast to utilitarian consumers, hedonic consumers use an exploratory search behavior that is undirected, less deliberate, and less focused when browsing information (Hoffman and Novak 1996, Janiszewski 1998, Moe 2003, Novak et al. 2003). In summary, utilitarian consumers differ from hedonic consumers in their information search behavior online.

Thus, information control may have different effects on utilitarian and hedonic consumers in facilitating their information seeking processes. High information control allows utilitarian consumers to search for relevant product information actively and directly, and spend as much time as necessary to read the relevant product information. Hence, a higher level of information control could facilitate the decision making of utilitarian consumers in obtaining and processing useful information efficiently. Regarding hedonic consumers, information control can also facilitate their information seeking processes by offering them the freedom to process information. However, the benefits of information control for hedonic consumers may be fewer than those for utilitarian consumers. Hedonic consumers are undirected and less deliberate when browsing information online and do not need to control the information content or the time of information seeking as much as utilitarian consumers do. Thus, we argue that the positive effects of information control are stronger for utilitarian consumers than for hedonic consumers.

The remainder of this paper is organized as follows. Section 2 presents the hypotheses and research model, and Section 3 demonstrates the method, with results presented in Section 4. Finally, Section 5 offers the conclusion, theoretical contribution, managerial implications, discussion, limitations, and future research.

\section{Hypothesis development and research model}

\subsection{Shopping online: controlling information flow}

As discussed in the previous section, information control can help consumers improve their shopping experiences. Information control offers consumers freedom and flexibility to select the information they seek (Kleinmuntz and Schkade 1993, Schkade and
Kleinmuntz 1994). Thus, information control may benefit consumers by satisfying their various information needs (Beatty and Smith 1987, Furse et al. 1984, Hauser et al. 1993), which may be based on particular motivations, knowledge background, and personal preferences. Furthermore, during the process of information search, consumers may acquire new knowledge and change their focus of information seeking occasionally. A higher level of information control could also provide the opportunity for consumers to search for information according to their evolution of knowledge. Hence, information control is a useful feature for online retailers to support the information seeking and decision making of consumers.

In contrast to traditional media, various levels of information control are able to be simultaneously observed on the Internet (McMillan and Hwang 2002). As mentioned, high information control (e.g., search engines) and low information control (e.g. pop-up ads) are common in e-commerce and can exist simultaneously in the same online stores. By contrast, traditional media (e.g., magazines, TV) offer merely one level of information control: either high or low. For instance, magazines have high information control, whereas TV has low information control. When people read a magazine, they can freely select the reading time, order, and information to read. Conversely, when people watch TV, they are merely able to decide to switch the channel or turn off the TV. Because different levels of information control are present on the Internet, the following question remains: How can online retailers leverage the different levels of information control to offer consumers personalized assistance in facilitating their information seeking and decision making behavior?

Notably, low information control does not mean that consumers do not have any control at all. The condition of low information control on the Internet is passive control, under which consumers can avoid reading information only by clicking a button or closing a window. Passive control allows consumers to ignore irrelevant or uninteresting information, but it does not provide them with chances to search for relevant or interesting information (Hwang et al. 2003).

The concept of information control can refer to either physical or perceived control. Physical control refers to the hardwired opportunity of information control embedded in objective features of information systems (IS) offered to users for making choices regarding information presentation (Liu and Shrum 2002). By contrast, perceived control is defined as "the feeling of the amount of control that people have over the process or outcome" (Bateson and Hui 1987). The current study primarily focused on the effects of physical control because website operators can directly manage it. However, for cases in which physical control is offered, consumers may not experience equivalent levels of perceived control (Bucy and Tao 2007, Song and Zinkhan 2008, Voorveld et al. 2011). For instance, the presence of search engines may not result in an increase in users' perception of control when they do not have motivations to use search engines. Previous research has shown that physical control and perceived control may be incongruent because of personal and situational factors (Bucy and Tao 2007, Lee et al. 2004, Liu and Shrum 2002, Tremayne 2005). Most importantly, perceived control may mediate the effects of physical control (Bucy and Tao 2007, Wu 2005). Therefore, the current study simultaneously assessed the effects of physical control and perceived control on the shopping experiences of online consumers.

Shopping experiences may include product information search, product evaluation, and purchase decision stages. When consumers shop online, they first seek product information and determine the information that they require. After gathering relevant information, consumers process the information and spend time on evaluating products. Finally, they make a purchase decision 
and cultivate overall attitudes toward websites. During these stages, consumers may be engaged in processing collected information that may lead them to generate attitudes toward products and commercial websites in general. In this study, shopping experiences were measured accordingly: involvement, product attitudes, and website satisfaction.

As previous studies have shown, information control facilitates enhancing users' flow (Huang 2012), perception of efficiency (Crutzen et al. 2012), cognitive involvement (Jiang et al. 2010), and attitudes toward websites (Chung and Ahn 2007, Hwang and McMillan 2002, Teo et al. 2003), and decreases their perception of product uncertainty (Weathers et al. 2007). High information control allows consumers to actively search and process the information they need by providing them with the freedom to choose what to read, in what order, and at what pace. Consequently, the selection process requires close attention from consumers and engages them in elaborating on the collected information (Fortin and Dholakia 2005, Jiang et al. 2010, Liu and Shrum 2002). Moreover, a high level of information control offers consumers the opportunities to spend as much time as they need to understand products of interest so that they can acquire knowledge about products and reduce perceived uncertainty. Therefore, consumers under the high information control condition evaluate products more favorably than do their counterparts under the low information control condition (Weathers et al. 2007). Hence, consumers may feel satisfied with their information seeking process and have positive attitudes toward websites (Chung and Ahn 2007, Hwang and McMillan 2002, Teo et al. 2003). In summary, consumers become more cognitively involved, generate more favorable attitudes toward products, and more satisfied with websites under the condition of high information control than consumers under the condition of low information control.

Although information control has positive effects on consumer involvement, product attitudes, and website satisfaction, recent studies have indicated that these effects of information control are not the same for all people (Sicilia et al. 2005, Wu and Lin 2006, 2012). One possible explanation for such inconsistent effects is the existence of contingent factors. Thus, this study adopted a contingency view to explore the effects of information control.

\subsection{Contingency view of information control}

The contingency view, which originated in organization theory, argues that there is no "best way" to manage an organization, and the effectiveness of each specific management method depends on different conditions (Galbraith 1973). Applying such a view to the fields of information technology and IS, previous research has shown that contingent characteristics of individuals and organizations are crucial to building an effective information system (Otley 1980, Reinking 2012). Similarly, contingent factors have been explored for the effects of information control in recent studies (Wu and Lin 2006, 2012). Wu and Lin $(2006,2012)$ found that consumer expertise and motivation were crucial contingent factors for the effects of information control. In addition to studies that have directly investigated information control, other research has revealed that the effects of interactivity, which are closely related to information control, are also contingent on individual characteristics. Liu and Shrum (2002) proposed that the effects of interactivity on user satisfaction may be a function of desire for control and browsing purposes. Amichai-Hamburger et al. (2004) also revealed that the concept of need for closure moderated the relationship between Internet interactivity and consumer preference when there was no time pressure. Sicilia et al. (2005) found that the concept of need for cognition is a moderator in the association between website interactivity and information processing. Therefore, the contingency view of information control has been verified by empirical results.
In addition to the mentioned empirical studies, the contingency view of information control is consistent with the concept of affordances, which refer to "the actionable properties between an object and an actor" (Gibson 1987, Norman 1999). For example, a chair has a flat surface that can sustain objects and provide people with sit-ability. Similarly, information control refers to the features that offer people the freedom to choose the reading content, order, and time of IS so that the concept of affordance is the essence of information control. Although affordances inhabit the physical features of the object, this concept still depends on the actor which interact with the object (Torenvliet 2003). For instance, a chair provides sit-ability affordance for an adult, but it does not provide the same affordance for a 1-month-old baby. Thus, the concept of affordances is contingent on the users interacting with it. Equally, the effects of information control also depend on the users interacting with it. Therefore, user factors serve as critical contingent factors for the effects of information control.

Zhang (2008) further proposed the construct of motivational affordances and argued that the design of affordances in IS must support users' motivations. People adopt systems to satisfy their different psychological, cognitive, social, and emotional needs; therefore, system design must consider their various motivations. Similarly, the design of information control should also account for people's motivations and offer "the properties of information systems that determine whether and how it can support one's motivation needs" (Zhang 2008). Online consumers have different shopping purposes when surfing commercial websites to acquire product information. The different shopping purposes of consumers may need various levels of information control to facilitate their online information seeking and decision making process. Hence, the objective of this research is to examine the contingent effects of shopping purposes on the relationship between information control and shopping experiences.

\subsection{Shopping purposes online: moderator of the effects of information control}

As argued in the study of Hirschman and Holbrook (1982), the shopping purposes of consumers can be categorized as "utilitarian" and "hedonic." Utilitarian purpose is defined as mission-critical, rational, decision-effective, and goal-oriented (Batra and Ahtola 1991, Hirschman and Holbrook 1982, Wolfinbarger and Gilly 2001). Hedonic purpose is described as shopping for amusement, enjoyment, fantasy, novelty, variety, surprise, awakening, and sensuality (Babin et al. 1994, Hirschman and Holbrook 1982). Although such a dichotomy of shopping purposes is simple, it is theoretically and empirically comprehensive. This dichotomy relates to the dual process model of human thinking which consists of rational and experiential thinking styles (Epstein 2003). This dichotomy is also parallel to previous empirical research of shopping behavior that describes consumers as functional vs. nonfunctional motivations (Sheth 1983), shopping as work vs. shopping as fun (Babin et al. 1994), economic vs. recreational (Bellenger and Korgaonkar 1980), and goal-oriented vs. experiential consumers (Novak et al. 2003). Therefore, such a dichotomy of utilitarian and hedonic purposes is valid and was used in the current study.

When consumers shop for utilitarian purpose, the task of shopping is deemed "work" (Babin et al. 1994). Utilitarian consumers aim to acquire product information of a targeted product to make high-quality decisions and complete the purchase task by a particular deadline. Thus, utilitarian consumers directly search for specific product information related to the needed product with prepurchase deliberation, by considering the product, service, and price features before purchase (Bloch et al. 1986, Hoffman 
and Novak 1996). Such an information seeking pattern adopted by utilitarians is called directed search behavior (Hoffman and Novak 1996, Novak et al. 2003), which is goal-driven and involves intensive attention and deliberation in the process of online information seeking (Janiszewski 1998). Conversely, when consumers shop for hedonic purpose, the task of shopping is nonfunctional, playful, and viewed as "fun" (Babin et al. 1994). In contrast to utilitarian consumers, hedonic consumers shop for an appreciation of experiences rather than for task completion (Babin et al. 1994). Hedonic consumers do not have specific shopping goals, substantial plans, or immediate needs for purchase (Janiszewski 1998, Wolfinbarger and Gilly 2001). In other words, hedonic consumers typically exhibit a nondirected search behavior. Compared with utilitarian consumers, hedonic consumers apply an exploratory search behavior, which is "not guided by goals or outcomes, but by the process itself" (Bloch et al. 1986, p. 121). Hence, exploratory search behavior is stimulus-driven and demands less attention, and less deliberation when a consumer browses product information (Hoffman and Novak 1996, Janiszewski 1998, Novak et al. 2003). In conclusion, utilitarian consumers differ from hedonic consumers in goal specificity and information seeking behavior.

High information control allows utilitarian consumers to actively search for product information related to their purchase goal and allocate as much time as necessary to read the relevant information. Hence, high information control provides them with the chance to collect useful information and efficiently complete their purchase task, which is essential for utilitarians, because they typically must meet a deadline for the involved purchase task. In other words, high information control meets the needs of utilitarians who want to take control over the information seeking and purchase process. Although high information control also provides hedonic consumers the freedom to browse interesting information, the benefits of high information control for hedonic consumers may not be as much for them. Hedonic consumers have no immediate or specific purchase goal such as searching for relevant product information to meet a deadline. The search choice of hedonic consumers does not involve deliberate decisions. Rather, it is driven by a continually changing goal (i.e. whatever interesting coming along the search process) (Deci and Ryan 1985, Hoffman and Novak 1996, Janiszewski 1998). Therefore, utilitarians need the freedom embedded in information control more than hedonic consumers do, and information control may incur different effects for utilitarian and hedonic consumers in facilitating their information seeking.

As discussed, information control can enhance consumer shopping experiences, including involvement, product attitudes, and website satisfaction, and we argue that the degree of enhancement can be different for utilitarian and hedonic consumers. For utilitarian consumers, high information control allows them to allocate most of their attentions on collecting and processing the relevant information and ignore the irrelevant information. Because utilitarian consumers must complete the purchase task by a deadline, they have strong motivation to search and process the relevant information. Thus, they could become highly engaged in information seeking activities and cognitively involved in collected information. By contrast, high information control allows hedonic consumers to widely browse various types of product information (Novak et al. 2003) because they do not allocate their attentions on specific products, like utilitarians. Therefore, hedonic consumers may not elaborate on information seeking process as much as utilitarian consumers do. Consequently, we argue that the positive relationships between information control and consumer involvement are stronger for utilitarian consumers than for hedonic consumers. Furthermore, we investigated the effects of both physical control and perceived control, as hypothesized in $\mathrm{H} 1 \mathrm{a}$ and $\mathrm{H} 1 \mathrm{~b}$ :
Hypothesis 1. Online shopping purpose (utilitarian vs. hedonic) moderates the positive effects of information control on consumer involvement.

Hypothesis 1a. The positive effect of physical control on consumer involvement is stronger for utilitarian consumers than for hedonic consumers.

Hypothesis 1b. The positive effect of perceived control on consumer involvement is stronger for utilitarian consumers than for hedonic consumers.

In addition to involvement, we also assessed the effects of information control on product attitudes. For utilitarian consumers, high information control allows them to spend as much time as they need on understanding the products to be purchased. Therefore, product uncertainty could be effectively decreased and favorable attitudes toward products could be formed. However, although high information control also allows hedonic consumers to freely read product information on websites, they spend less time on each product than utilitarian consumers do because their attention is divided among products (Chiou and Ting 2011). Hedonic consumers may not be able to comprehend product attributes as much as utilitarians can because of divided attention. Thus, hedonic consumers may also generate favorable attitudes toward a product because of information control, but not as much as utilitarian consumers do. Hence, we argue that the positive relationships between information control and consumers' product attitudes are stronger for utilitarian consumers than for hedonic consumers. Similarly, we assessed the effects of both physical control and perceived control, as hypothesized in $\mathrm{H} 2 \mathrm{a}$ and $\mathrm{H} 2 \mathrm{~b}$ :

Hypothesis 2. Online shopping purpose (utilitarian vs. hedonic) moderates the positive effects of information control on consumer product attitudes.

Hypothesis 2a. The positive effect of physical control on consumer product attitudes is stronger for utilitarian consumers than for hedonic consumers.

Hypothesis 2b. The positive effect of perceived control on consumer product attitudes is stronger for utilitarian consumers than for hedonic consumers.

Finally, the effects of information control on website satisfaction were also studied. Utilitarian consumers need the freedom and control to achieve their purchase task, and a high level of information control fits such needs of utilitarian consumers (Martínez-López et al. 2014, Wolfinbarger and Gilly 2001). For utilitarian consumers, high information control embedded in websites allows them to gather the product information they want and solve the problem in a timely manner. Therefore, utilitarian consumers are satisfied with the assistance of information control and further generate favorable attitudes toward websites. Although high information control also allows hedonic consumers to freely surf commercial websites, hedonic consumers perform such tasks without time pressure to achieve the shopping goal. Thus, hedonic consumers may not need such freedom and control as much as utilitarian consumers do, and hence may not feel as appreciative and satisfied with the assistance of information control embedded in websites. Therefore, we argue that the positive relationships between information control and website satisfaction are stronger for utilitarian consumers than for hedonic consumers. Furthermore, we examined the effects of both physical control and perceived control, as stated in $\mathrm{H} 3 \mathrm{a}$ and $\mathrm{H3b}$ : 
Hypothesis 3. Online shopping purpose (utilitarian vs. hedonic) moderates the positive effects of information control on consumer website satisfaction.

Hypothesis 3a. The positive effect of physical control on consumer website satisfaction is stronger for utilitarian consumers than for hedonic consumers.

Hypothesis 3b. The positive effect of perceived control on consumer website satisfaction is stronger for utilitarian consumers than for hedonic consumers.

\section{Methodology}

\subsection{Research design}

The method of laboratory experimentation was adopted to test the proposed hypotheses. In this study, there were two independent variables: physical information control (high vs. low) and online shopping purpose (utilitarian vs. hedonic). Both independent variables were between-subject variables; hence, there were four $(2 \times 2)$ conditions in total. The manipulation of both independent variables was validated by adopting the scales of perceived information control and perceived purposefulness. Furthermore, the measurement of perceived control was also used to test the proposed hypotheses pertaining to perceived control. The task of the participants was to seek product information on the assigned website and then evaluate their own degrees of involvement, product attitudes, and website satisfaction, which were the dependent variables in this study.

\subsection{Test material of the independent variables}

We constructed the commercial websites used for this study by adapting product information from real commercial websites and presenting it in two forms of information control, high and low. In the form of high information control, the product information was presented in a combination of images, hyperlinks, and text, from which users could actively and freely choose what to read, how long to read, and what order in which to read. In the form of low information control, product information was presented in video with a predetermined pace and order. Notably, the product information presented in both information control conditions was the same to prevent possible confounding variables. The manipulation check for physical information control was performed by using the scale of perceived information control adapted from the research of Liu (2003).

The scenarios of task-oriented and recreational purposes developed by Chiou and Ting (2011) and Kaltcheva and Weitz (2006) were adapted to induce the utilitarian and hedonic purposes, respectively. In the scenario of utilitarian purpose, the participants were instructed to buy the target product for a very important reason and hence had to make a high-quality purchase decision. Participants were then directed to collect as much relevant information for their purchase decisions as they could on the given commercial website. Conversely, in the scenario of hedonic purpose, participants were instructed to browse the given website for fun in their leisure time, with the chance of finding some products that highly interested them. The manipulation check for shopping purpose was adapted from the scale of Laczniak and Muehling (1993), which measured the relevance of a shopping task. Three questions were asked to determine whether the consumers paid attention to the product advertisements as though they were considering buying the products or had an immediate need for them (for the details of measurement items, please see Appendix A). These questions measured the most crucial difference between utilitarian consumers and hedonic consumers; that is, shopping purposefulness (Babin et al. 1994, Batra and Ahtola 1991, Novak et al. 2003). Therefore, the scale was adapted to determine whether the manipulation of shopping purpose was successful. A higher level of perceived purposefulness represented a utilitarian purpose, whereas a lower level of perceived purposefulness represented a hedonic purpose. The items on perceived control and perceived purposefulness were scored on a 7-point Likert scale, with responses ranging from 1 (strongly disagree) to 7 (strongly agree).

Products for participants to purchase in the experiment were chosen based on the following criteria. First, the products had to be of interest to students and young people, because these populations constitute a significant portion of online users, as well as of our potential sample. Second, the price of the products had to be affordable to students and young people. Third, to avoid possible brand biases, the market share of the products could not be highly concentrated, nor could the market be dominated by merely a low number of brands. Finally, four products (i.e., an electronic translator, running shoes, a bicycle, and a notebook) were chosen. For each of the four products, we chose the brand that had the third or fourth largest market share in Taiwan, where the data were collected. Relevant product information was adapted from existing online websites and presented under the conditions of high and low information control. Notably, the information content displayed in both controls was the same to prevent possible confounding effects of information content and information quantity. Furthermore, the names of the websites were fabricated to exclude the confounding effects typically inherent in actual websites, including product types and website reputation.

\subsection{Measurements of the dependent variables}

The measurements of the constructs were scales adopted from previous relevant research. The measurements of user satisfaction with the websites and user attitudes toward the products were adapted from McKinney et al. (2002) and Herr et al. (1991), respectively. The response forms of the scales of website satisfaction and user attitudes toward products were 7-point semantic differential scales, with responses ranging from 1 (very dissatisfied) to 7 (very satisfied). The construct of involvement was measured with the scale of Advertising Message Involvement (AMI) (Laczniak and Muehling 1993). The response form of the scale of involvement was a 7-point Likert scale, with responses ranging from 1 (strongly disagree) to 7 (strongly agree). The measurement items and their sources are presented in Appendix A. All the questions were adapted based on the online purchase situation.

\subsection{Participants}

Participants were recruited through advertisements posted on various websites, such as online forums and social network sites. In total, 292 volunteer participants were recruited; 141 were randomly assigned to the utilitarian condition, and 151, to the hedonic condition. Among the 141 utilitarian participants, 68 participants were randomly assigned to the high information control condition, and 73 , to the low information control condition. Among the 151 hedonic participants, 76 participants were randomly assigned to the high control, and 75, to the low control condition.

The demographic distributions of the sample, as shown in Table 1, were compared against the data on Insightxplorer (2013), the largest market survey company in Taiwan, to assess the external validity of the sample. As illustrated in Table 1, the distributions of age and education in our sample differed from 
those reported in the Insightxplorer survey, in that our sample was younger, better educated, and student-saturated $(86.3 \%$ in our sample vs. $25.9 \%$ in Insightxplorer). These three characteristics could be highly correlated because students tend to be younger and more highly educated. Because our sample was studentsaturated, the representativeness of the sample was a concern. Therefore, the $\mathrm{K}-\mathrm{S}$ test was used to evaluate the differences between the student and nonstudent participants in their responses to the measurements in this study. If they did not differ significantly from each other, then the student-saturated sample should not be subject to external validity, and the data of students and nonstudents would be combined for further analysis.

The results of the K-S test indicated no significant differences between the student and nonstudent participants regarding their evaluations of involvement $\left(D=0.16<D_{(0.025,252,40)}=0.23, p=0.38\right)$, product attitudes $\left(D=0.12<D_{(0.025,252,40)}=0.23, p=0.71\right)$, website satisfaction $\left(D=0.18<D_{(0.025,252,40)}=0.23, p=0.22\right)$, perceptions of information control $\left(D=0.09<D_{(0.025,252,40)}=0.23, p=0.95\right)$, and perceptions of purposefulness $\left(D=0.13<D_{(0.025}, 252,40\right)=0.23$, $p=0.58$ ). In other words, there were no significant differences in the responses of the students and nonstudents; hence, the external validity would not be a concern for the student-saturated sample in this study. Therefore, the data of the student and nonstudent samples were combined for further analysis.

\subsection{Procedure}

Participants were invited to our behavioral science lab to participate in the experiment. They were first instructed how to perform the task of the experiment, after which they signed a consent form if they agreed to participate. Those who agreed to participate were randomly assigned to one of the four conditions, as described in Section 3.1. They were then directed to read the scenario of the shopping purpose and to browse the product information of the four products on the assigned website. After they viewed the information on each of the four products, they were asked to answer questions regarding their evaluations of involvement, satisfaction with websites, and attitudes toward products. Afterward, the participants answered questions regarding their perceptions of information control on the assigned website and their evaluations of their purposefulness when collecting product information from the websites. Finally, they answered questions about their demographic information. Each participant spent $40 \mathrm{~min}$ on average to complete the entire experiment and received NT\$150 as an incentive for participation.

\section{Table 1}

Demographic information of the sample of this study comparing against that of Insightxplorer's report.

\begin{tabular}{lll}
\hline Demographic information & $\begin{array}{l}\text { Sample of this } \\
\text { study (\%) }\end{array}$ & $\begin{array}{l}\text { Insightxplorer's } \\
\text { report (\%) }\end{array}$ \\
\hline Gender & & \\
Male & 57.19 & 51.20 \\
Female & 42.81 & 48.80 \\
Age & & \\
10-19 & 22.95 & 19.00 \\
$21-29$ & 72.94 & 21.70 \\
30-39 & 4.11 & 23.70 \\
Education & & \\
Master degrees or above & 14.46 & 7.80 \\
University degrees & 27.06 & 50.10 \\
High school diploma or below & 41.52 & 42.00 \\
Occupation & & \\
Student & 86.30 & 74.10 \\
Non-student & 13.70 & \\
\hline
\end{tabular}

\subsection{Data analysis}

For the empirical results, we first evaluated the reliability and validity of the measurements, tested the assumptions of the statistical methods for hypothesis testing, and then reported the results of inferential statistics. First, the reliability and validity of the measurements, including the dependent variables and manipulation checks of the independent variables, were evaluated. The set of measurements of each construct was called the scale, and the individual measurements under each scale were the items. The tests of reliability consisted of item reliability and scale reliability (also called construct reliability) (Carmines and Zeller 1979, Fornell and Larcker 1981, Hair et al. 2010, Hulland 1999). Item reliability was assessed with the factor loading of each individual item on its corresponding construct, and scale reliability was assessed in terms of Cronbach's alpha and composite reliability (CR) (Carmines and Zeller 1979, Fornell and Larcker 1981, Hair et al. 2010, Hulland 1999). The tests of validity included convergent validity and discriminant validity (Fornell and Larcker 1981). Convergent validity was tested in terms of the significance of each factor loading and average variance extracted (AVE) for each construct (Fornell and Larcker 1981, Gefen and Straub 2005). The discriminant validity of each individual item level was tested by comparing the factor loading of each item on its construct and its cross loadings on other constructs. The discriminant validity of the construct level was assessed by comparing the squared roots of the AVEs and the correlation coefficients between the corresponding construct and other constructs (Fornell and Larcker 1981, Hair et al. 2013). Second, a manipulation check was conducted for the constructs of physical information control and shopping purpose. Finally, the data were tested to determine whether the data met the assumptions of the inferential statistical methods to be used. Because the construct of physical control is categorical, and that of perceived control, continuous, the methods of MANOVA and multiple regression were appropriate for testing the effects of physical information control and perceived information control, respectively. Therefore, the assumptions of MANOVA and multiple regression analysis, including multivariate normality and multicollinearity, were tested (Field and Miles 2010, Pallant 2010, Stevens 2012). When one of the assumptions of MANOVA or multiple regression analysis was not met, PLS analysis was adopted for testing the hypotheses.

\section{Empirical results}

4.1. Reliability and validity, manipulation check, and assumption tests of statistical methods

The reliability and validity of the measurements were evaluated first. The relationships between constructs and their indicators in this study are reflective. A full set of descriptive statistics for each item is presented in Appendix B. The results of reliability, consisting of item reliability and scale reliability, are presented in Table 2, which reports the standardized factor loading, $t$ value of factor loading, Cronbach's alpha, composite reliability (CR), and average variance extracted (AVE). As shown in Table 2, except for one item from the scale of perceived information control (Co3), the factor loadings for all items, which ranged from 0.70 to 0.96 and exceeded the recommended threshold of 0.70 , suggested a satisfactory level of item reliability (Carmines and Zeller 1979, Hulland 1999). Therefore, this item (Co3) was dropped because of its low degree of factor loading (0.03) on its corresponding construct (Nunnally 1978). In total, 21 items were retained for further analysis. The Cronbach's alpha values for all scales ranged from 0.73 to 0.97 , and the values of CR for all scales ranged from 0.85 to 0.98 . All 
Table 2

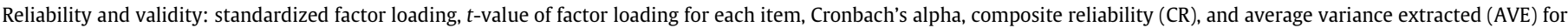
each construct.

\begin{tabular}{|c|c|c|c|c|c|c|}
\hline Constructs & Items & $\begin{array}{l}\text { Standardized factor } \\
\text { loadings }\end{array}$ & $\begin{array}{l}t \text {-Value of factor } \\
\text { loadings }^{\mathrm{b}}\end{array}$ & $\begin{array}{l}\text { Cronbach's } \\
\text { alpha }\end{array}$ & $\begin{array}{l}\text { Composite } \\
\text { reliability }\end{array}$ & $\begin{array}{l}\text { Average variance } \\
\text { extracted }\end{array}$ \\
\hline Thresholds & & $>0.70$ & $>1.96$ & $>0.70$ & $>0.70$ & $>0.50$ \\
\hline \multirow{5}{*}{ Involvement (In) } & In1 & 0.96 & 172.85 & 0.97 & 0.98 & 0.90 \\
\hline & $\operatorname{In} 2$ & 0.95 & 122.28 & & & \\
\hline & In 3 & 0.96 & 166.79 & & & \\
\hline & In 4 & 0.96 & 184.24 & & & \\
\hline & In5 & 0.92 & 80.67 & & & \\
\hline \multirow[t]{4}{*}{ Product attitude (Ap) } & Ap1 & 0.91 & 44.97 & 0.87 & 0.92 & 0.73 \\
\hline & Ap2 & 0.70 & 14.54 & & & \\
\hline & Ap3 & 0.89 & 45.51 & & & \\
\hline & Ap4 & 0.91 & 43.56 & & & \\
\hline \multirow[t]{6}{*}{ Website satisfaction (Sa) } & Sa1 & 0.92 & 89.06 & 0.96 & 0.97 & 0.82 \\
\hline & Sa2 & 0.89 & 60.74 & & & \\
\hline & Sa3 & 0.90 & 55.22 & & & \\
\hline & Sa4 & 0.92 & 100.88 & & & \\
\hline & Sa5 & 0.91 & 88.27 & & & \\
\hline & Sa6 & 0.89 & 57.11 & & & \\
\hline \multirow[t]{3}{*}{ Perceived control $(\mathrm{Co})^{\mathrm{a}}$} & Co1 & 0.90 & 45.30 & 0.89 & 0.93 & 0.82 \\
\hline & $\mathrm{Co} 2$ & 0.93 & 93.20 & & & \\
\hline & Co4 & 0.89 & 43.35 & & & \\
\hline \multirow{3}{*}{$\begin{array}{l}\text { Perceived purposefulness } \\
\quad(\mathrm{Pu})\end{array}$} & Pu1 & 0.77 & 14.39 & 0.73 & 0.85 & 0.66 \\
\hline & Pu2 & 0.93 & 70.87 & & & \\
\hline & Pu3 & 0.72 & 10.73 & & & \\
\hline
\end{tabular}

a One item (Co3) of the perceived control was dropped due to its low degree of factor loading (lower than 0.70).

b All factor loadings are highly significant at the level of 0.001 .

of the Cronbach's alpha values and CRs exceeded the suggested thresholds of 0.70 , indicating an acceptable level of scale reliability (Fornell and Larcker 1981, Hair et al. 2010). In brief, the measurements used in this study had sufficient levels of reliability.

The results of validity, including convergent validity and discriminant validity, are presented in Tables 2-4. As illustrated in Table 2, all factor loadings were highly significant at the level of 0.001 . The values of AVEs for all scales, ranging from 0.66 to 0.90 , exceeded the recommended threshold of 0.50 (Fornell and Larcker 1981). The results indicate that the convergent validities of all of the scales were acceptable (Fornell and Larcker 1981, Gefen and Straub 2005). Table 3 shows the test of discriminant validity at the individual item level. The bold values in Table 3, representing the factor loadings of items on their constructs, are higher than all of their cross loadings on other constructs. Table 4 reports the test results of discriminant validity of the construct level. The diagonal numbers in Table 4, representing the squared roots of the AVEs for each construct, are higher than the offdiagonal values, the correlation coefficients between each construct, and the other constructs. Hence, the discriminant validity was satisfactory at both the individual item level and the construct level (Fornell and Larcker 1981, Hair et al. 2013). In summary, the measurements used in this study had sufficient levels of validity.

The manipulation of the independent variables (i.e., physical control and shopping purpose) was also validated. Participants who were assigned to the utilitarian group reported a significantly

Table 3

Discriminant validity of individual item level: factor loadings of items and cross loadings.

\begin{tabular}{|c|c|c|c|c|c|}
\hline \multirow[t]{2}{*}{ Items } & \multicolumn{5}{|l|}{ Constructs } \\
\hline & Involvement (In) & Product attitude (Ap) & Website Satisfaction (Sa) & Perceived control (Co) & Perceived purposefulness (Pu) \\
\hline In1 & 0.96 & 0.64 & 0.56 & 0.29 & 0.19 \\
\hline In2 & 0.95 & 0.61 & 0.56 & 0.28 & 0.21 \\
\hline In3 & 0.96 & 0.63 & 0.58 & 0.28 & 0.24 \\
\hline In4 & 0.96 & 0.66 & 0.58 & 0.30 & 0.24 \\
\hline In5 & 0.92 & 0.62 & 0.54 & 0.27 & 0.23 \\
\hline Ap1 & 0.70 & 0.91 & 0.66 & 0.32 & 0.20 \\
\hline Ap2 & 0.34 & 0.70 & 0.41 & 0.25 & 0.19 \\
\hline Ap3 & 0.61 & 0.89 & 0.63 & 0.27 & 0.26 \\
\hline Ap4 & 0.62 & 0.91 & 0.63 & 0.31 & 0.22 \\
\hline Sa1 & 0.58 & 0.66 & 0.92 & 0.33 & 0.25 \\
\hline $\mathrm{Sa} 2$ & 0.54 & 0.64 & 0.89 & 0.31 & 0.27 \\
\hline Sa3 & 0.52 & 0.62 & 0.90 & 0.30 & 0.27 \\
\hline Sa4 & 0.53 & 0.63 & 0.92 & 0.34 & 0.21 \\
\hline Sa5 & 0.53 & 0.62 & 0.91 & 0.40 & 0.29 \\
\hline Sa6 & 0.52 & 0.55 & 0.89 & 0.35 & 0.18 \\
\hline Co1 & 0.22 & 0.30 & 0.34 & 0.90 & 0.25 \\
\hline $\mathrm{Co} 2$ & 0.29 & 0.31 & 0.35 & 0.93 & 0.26 \\
\hline Co 4 & 0.29 & 0.30 & 0.33 & 0.89 & 0.33 \\
\hline Pu1 & 0.23 & 0.17 & 0.22 & 0.35 & 0.77 \\
\hline $\mathrm{Pu} 2$ & 0.25 & 0.27 & 0.23 & 0.28 & 0.93 \\
\hline Pu3 & 0.08 & 0.17 & 0.22 & 0.12 & 0.72 \\
\hline
\end{tabular}

Note: The bold values are factor loadings of items. 
Table 4

Discriminant validity of construct level: the squared roots of the AVEs and the correlation coefficients between the corresponding construct and other constructs.

\begin{tabular}{llllll}
\hline Constructs & 1 & 2 & 3 & 4 & 5 \\
\hline 1. Involvement & 0.95 & & & & \\
2. Product attitude & 0.67 & 0.86 & & & \\
3. Website satisfaction & 0.59 & 0.69 & 0.91 & & \\
4. Perceived control & 0.30 & 0.34 & 0.38 & 0.91 & \\
5. Perceived purposefulness & 0.23 & 0.26 & 0.27 & 0.31 & 0.81 \\
\hline
\end{tabular}

Note: The diagonal numbers are the squared root of AVEs.

higher level of perceived purposefulness than their hedonic counterparts ( 4.67 vs. $3.87, t(289)=5.83$, $S e=0.14, p<0.001)$. Furthermore, participants who were assigned the website with high physical information control perceived a higher level of information control than did their counterparts under the low physical information control condition (5.23 vs. 4.19, $t(272)=6.25$, $\mathrm{Se}=0.17, p<0.001)$. In other words, the manipulation of the independent variables was successful.

Before MANOVA was conducted to examine the effects of physical information control and multiple regression analysis for the effects of perceived information control, the assumptions of both statistical methods were assessed (Field and Miles 2010, Pallant 2010, Stevens 2012). The results of Mardia's coefficient showed that the multivariate distribution (measured in terms of skewness and kurtosis) of the dependent variables in the group of high control $\times$ hedonic was significantly different from the multivariate normal distribution (skewness: 46.2, $p<0.001$, kurtosis: 4.44, $p<0.001$ ) (Kim and Timm 2007). In other words, the data did not meet the assumption of multivariate normality of MANOVA, and it hence could not be used for this study. Because MANOVA was not used, multicollinearity was not evaluated. Therefore, partial least squares (PLS) was used for testing the effects of physical control because it does not assume normal distribution or multicollinearity, particularly for a reflective measurement model (Diamantopoulos and Winklhofer 2001, Hair et al. 2013).

The results of the normality assumption of residuals for the multiple regression analysis show that the distributions of residuals of product attitudes $(p>0.15)$ and website satisfaction $(p>0.15)$ did not significantly differ from the normal distribution, but the distribution of involvement was significantly different from the normal distribution $(p<0.05)$. In other words, the distributions of website satisfaction and product attitudes were normal, but that of involvement was not. Therefore, the data on involvement were transformed by adopting the Box-Cox transformation function (variable ${ }^{\lambda}-1 / \lambda, \lambda=1.30$ ) (Box and Cox 1964). After transformation, the distribution of residuals of involvement was the same as the normal distribution statistically $(p=0.14)$. In other words, the assumption of normality was met for the use of multiple regression analysis.
The multicollinearity assumption for the multiple regression analysis was also assessed by using variance inflation factor (VIF) values. The results indicated that the VIF values of the interaction terms (i.e., shopping purpose $\times$ perceived information control) exceeded 10 for all of the dependent variables. In other words, there was a multicollinearity problem between the independent variables and their interaction terms. Because of multicollinearity, the data on the independent variable (i.e., perceived control) were transformed using the mean-centering method (Aiken and West 1991). After the data on perceived control were transformed, the results showed that their VIF values were lower than 10 , suggesting that the problem of multicollinearity was eliminated (Cohen et al. 2003). The data also met the assumption of multicollinearity for the use of multiple regression analysis after transformation. Therefore, multiple regression analysis was used for testing the effects of perceived information control.

\subsection{Effects of physical information control}

Fig. 1 presents the effects of physical control on the three dependent variables for utilitarian and hedonic consumers. On average across the two shopping purpose groups, the participants under the high physical control condition had higher levels of consumer involvement, product attitudes, and website satisfaction than their counterparts under the low physical control condition (involvement: 4.91 vs. 4.47 ; product attitudes: 4.62 vs. 4.22 ; website satisfaction: 4.68 vs. 4.08 ). As discussed in the previous section, the effects of physical control were analyzed using PLS analysis. In the PLS analysis, the two independent variables, being categorical, were converted into dummy variables, with 0 representing low physical control or hedonic purpose and 1 representing high physical control or utilitarian purpose (Hair et al. 2013). Table 5 presents the results of the effects of PLS analysis. Before examining the interaction effects of physical control and shopping purpose, we first determined the simple main effects of physical control for both shopping purpose groups. As shown in Table 5, the positive effects of physical control on the three dependent variables were all highly significant (involvement: $\beta=0.26, p<0.001$; product attitudes: $\beta=0.31, \quad p<0.001$; website satisfaction: $\beta=0.37, p<0.001)$. In other words, physical control has simple main effects on consumer involvement, product attitudes, and website satisfaction.

The effects of physical control appeared in both the utilitarian group and the hedonic group. As shown in Fig. 1, utilitarian participants under the high physical control condition reported higher levels of consumer involvement, product attitudes, and website satisfaction than their counterparts under the low control condition (involvement: 5.26 vs. 4.52 ; product attitudes: 4.87 vs. 4.27 ; website satisfaction: 4.95 vs. 4.24). Similarly, hedonic participants reported higher levels of consumer involvement, product attitudes,

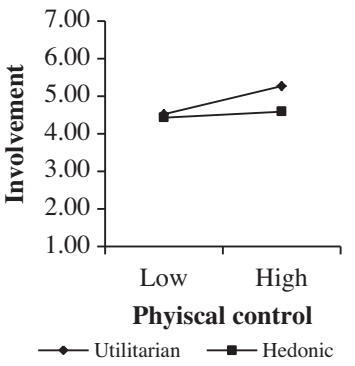

a

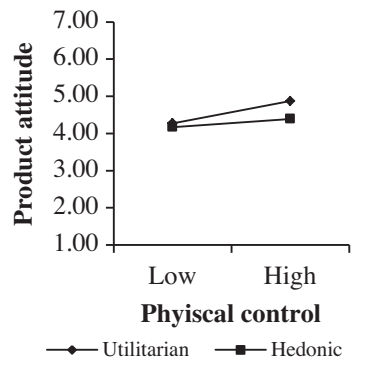

b

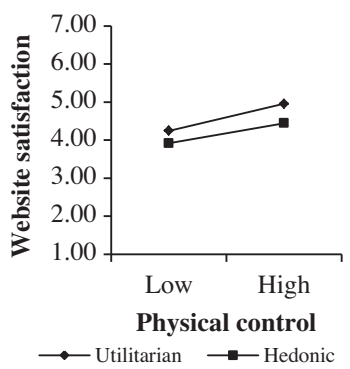

$\mathrm{c}$

Fig. 1. Effects of physical control on consumer involvement, product attitude and website satisfaction for utilitarian vs. hedonic consumers. 
Table 5

Results of PLS analysis for the effects of physical control: both shopping purpose groups, utilitarian group, and hedonic group (Physical control and shopping purpose as dummy variables).

\begin{tabular}{|c|c|c|c|c|}
\hline \multirow[t]{2}{*}{ Data } & \multirow{2}{*}{$\begin{array}{l}\text { Independent } \\
\text { variable }\end{array}$} & \multicolumn{3}{|c|}{ Dependent variables } \\
\hline & & Involvement & $\begin{array}{l}\text { Product } \\
\text { attitude }\end{array}$ & $\begin{array}{l}\text { Website } \\
\text { satisfaction }\end{array}$ \\
\hline $\begin{array}{l}\text { Both shopping } \\
\text { purpose } \\
\text { groups }\end{array}$ & $\begin{array}{l}\text { Physical } \\
\text { control } \\
\text { Adjusted } R^{2}\end{array}$ & $\begin{array}{l}0.26^{* * *} \\
(0.05) \\
0.07\end{array}$ & $\begin{array}{l}0.31^{* * *} \\
(0.05) \\
0.09\end{array}$ & $\begin{array}{l}0.37^{* * *} \\
(0.05) \\
0.13\end{array}$ \\
\hline Utilitarian group & $\begin{array}{l}\text { Physical } \\
\text { control } \\
\text { Adjusted } R^{2}\end{array}$ & $\begin{array}{l}0.42^{\text {*** }} \\
(0.06) \\
0.17\end{array}$ & $\begin{array}{l}0.41^{* * *} \\
(0.06) \\
0.16\end{array}$ & $\begin{array}{l}0.42^{\text {*** }} \\
(0.07) \\
0.17\end{array}$ \\
\hline Hedonic group & $\begin{array}{l}\text { Physical } \\
\text { control } \\
\text { Adjusted } R^{2}\end{array}$ & $\begin{array}{l}0.12(0.10) \\
0.01\end{array}$ & $\begin{array}{l}0.27^{* * *} \\
(0.07) \\
0.06\end{array}$ & $\begin{array}{l}0.35^{* * *} \\
(0.06) \\
0.12\end{array}$ \\
\hline \multicolumn{2}{|c|}{$\begin{array}{l}\text { Tests of moderating effects of } \\
\text { shopping purpose }\end{array}$} & Involvement & $\begin{array}{l}\text { Product } \\
\text { attitude }\end{array}$ & $\begin{array}{l}\text { Website } \\
\text { satisfaction }\end{array}$ \\
\hline \multirow{2}{*}{\multicolumn{2}{|c|}{$\begin{array}{l}t \text {-Value } \\
d f\end{array}$}} & $2.65^{* *}$ & $1.68^{*}$ & 0.75 \\
\hline & & 248 & 288 & 286 \\
\hline
\end{tabular}

Note: (): standard error; ${ }^{*} p<0.05 ;{ }^{* *} p<0.01 ;{ }^{* * *} p<0.001$.

and website satisfaction when given a high physical control than their counterparts given a low control (involvement: 4.59 vs. 4.43; product attitude: 4.39 vs. 4.17; website satisfaction: 4.44 vs. 3.92). Most importantly, the differences in the high vs. low physical control in terms of the three dependent variables were even greater for utilitarian consumers than

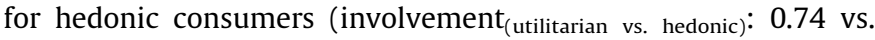
0.16 ; product attitudes (utilitarian vs. hedonic): 0.60 vs. 0.22 ; website

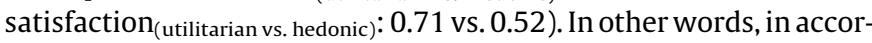
dance with Hypotheses 1a, 2a and 3a, the effects of physical control are stronger for utilitarian consumers than for hedonic consumers.

To determine whether the effects of physical control were significantly stronger for utilitarian consumers than for hedonic consumers (i.e., positive interaction), PLS multigroup analysis (PLS-MGA) was used because shopping purpose is categorical (Hair et al. 2013). As shown in Table 5, the positive interactions between physical control and online shopping purpose were statistically significant for the dependent variable of involvement $(t(248)=2.65, p<0.01)$ and for product attitudes $(t(288)=1.68$, $p<0.05)$, but not significant for website satisfaction $(t(286)$ $=0.75, p=0.23$ ). In short, Hypotheses $1 \mathrm{a}$ and $2 \mathrm{a}$ are strongly supported, and Hypothesis 3a is not statistically supported, according to the empirical results.

In conclusion, the results of consumer involvement and product attitudes consistently suggest a positive interaction between physical control and online shopping purpose. In other words, the positive effect of physical control is stronger for utilitarian consumers than for hedonic consumers. As discussed in the literature review, the level of control that consumers perceive could differ from the control that is provided in the physical features of IS. Therefore, the effects of perceived information control were also assessed in this research.

\subsection{Effects of perceived information control}

Fig. 2 presents the procedure suggested by Aiken and West (1991), showing the effects of perceived control on the three dependent variables for both utilitarian and hedonic consumers. As shown in the figure, the relationships between perceived control and the three dependent variables (i.e., consumer involvement, product attitudes, and website satisfaction) were all positive. In particular, in accordance with the predictions of Hypotheses $1 \mathrm{~b}$, $2 \mathrm{~b}$, and $3 \mathrm{~b}$, the positive slopes of perceived control were steeper for utilitarian consumers that for hedonic consumers. In other words, the effects of perceived control are stronger for utilitarian consumers than for hedonic consumers.

To assess the significance of the effects of perceived control, multiple regression analysis was used, as discussed. Because the

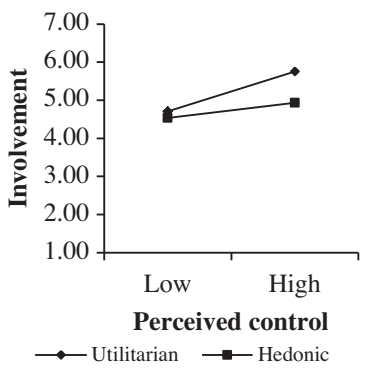

a

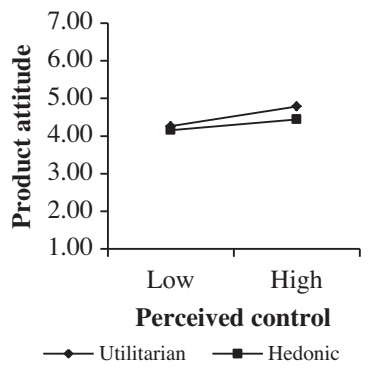

b

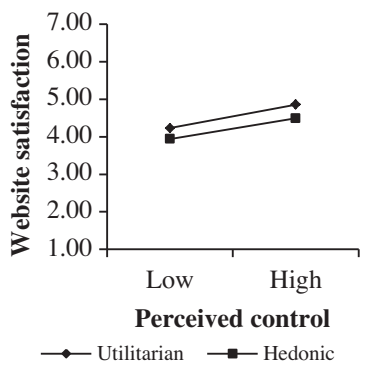

C

Fig. 2. Effects of perceived control on consumer involvement, product attitude and website satisfaction for utilitarian vs. hedonic consumers.

Table 6

Results of multiple regression analysis for the effects of perceived control (shopping purpose as a dummy variable).

\begin{tabular}{|c|c|c|c|c|c|c|}
\hline & \multicolumn{6}{|c|}{ Dependent variables } \\
\hline & \multicolumn{2}{|c|}{ Involvement } & \multicolumn{2}{|c|}{ Product attitude } & \multicolumn{2}{|c|}{ Website satisfaction } \\
\hline & Model 1 & Model 2 & Model 1 & Model 2 & Model 1 & Model 2 \\
\hline Independent variables & $\beta$ & $\beta$ & $\beta$ & $\beta$ & $\beta$ & $\beta$ \\
\hline Perceived control & $0.27^{* * *}$ & $0.15^{*}$ & $0.31^{* * *}$ & $0.22^{* *}$ & $0.35^{* * *}$ & $0.33^{* * *}$ \\
\hline Shopping purpose & $0.19^{* * *}$ & $0.19^{* * *}$ & $0.17^{* * *}$ & $0.17^{* * *}$ & $0.20^{* * *}$ & $0.20^{* * *}$ \\
\hline Shopping purpose * Perceived control & & $0.17^{*}$ & & $0.13^{*}$ & & 0.03 \\
\hline Adjusted $R^{2}$ & 0.12 & 0.13 & 0.14 & 0.14 & 0.17 & 0.17 \\
\hline$\triangle R^{2}$ & & $0.02^{*}$ & & $0.01^{*}$ & & 0.001 \\
\hline$F$ & $20.60^{* * *}$ & $15.63^{* * *}$ & $23.82^{* * *}$ & $16.92^{* * *}$ & $31.72^{* * *}$ & $21.15^{* * *}$ \\
\hline$d f$ & $(2,289)$ & $(3,288)$ & $(2,289)$ & $(3,288)$ & $(2,289)$ & $(3,288)$ \\
\hline
\end{tabular}

Note: ${ }^{*} p<0.05 ;{ }^{* *} p<0.01 ;{ }^{* * *} p<0.001 ; \triangle R^{2}$ indicates the effect size added. 
independent variable of shopping purpose is a categorical variable, it was converted into a dummy variable (Cohen et al. 2003), with 0 representing hedonic purpose and 1 representing utilitarian purpose. The main effects of perceived control and online shopping purpose were tested in Model 1, and the interaction effects of both constructs were tested in Model 2, for the three dependent variables. The results of multiple regression analysis are shown in Table 6 . The results of Model 1 showed perceived control to be positively and significantly related to the three dependent variables (involvement: $\beta=0.27, p<0.001$; product attitudes: $\beta=0.31, p<0.001$; website satisfaction: $\beta=0.35, p<0.001$ ). Similar to the results of physical control, perceived control also has simple main effects on these three dependent variables.

The results of Model 2 listed in Table 6 show the interaction effects of perceived control and shopping purposes. The positive interactions between perceived control and shopping purpose were statistically significant for involvement $(\beta=0.17, p<0.05)$ and for product attitudes $(\beta=.13, p<0.05)$, but not significant for website satisfaction $(\beta=0.03, p=0.34)$. Hypotheses $1 \mathrm{~b}$ and $2 \mathrm{~b}$ are strongly supported, but Hypothesis $3 \mathrm{~b}$ is not statistically supported. In other words, the positive effects of perceived control on user involvement and product attitudes were significantly stronger for utilitarian consumers than for hedonic consumers. In summary, Hypotheses 1a, 2a, 1b, and 2b are empirically supported, whereas Hypotheses $3 \mathrm{a}$ and $3 \mathrm{~b}$ are not. The positive effects of physical control and perceived control are stronger for utilitarian consumers than for hedonic consumers according to the data of user involvement and product attitudes but not to those of website satisfaction.

\section{Conclusion, contribution, managerial implications, discussion, limitations, and future research}

\subsection{Conclusion, theoretical contribution, and managerial implications}

This study investigated how information control affects consumer shopping experiences, including involvement, product attitudes, and website satisfaction, during online information-seeking process, and how such effects are moderated by consumer shopping purposes. The empirical results show that both types of physical control and perceived control enhance consumer involvement, product attitudes, and website satisfaction. Most importantly, as predicted by the hypotheses, information control has stronger effects on involvement and product attitudes for utilitarian consumers than for hedonic consumers. However, such effects are not apparent in the results for website satisfaction. Hypotheses 1 and 2 are supported, whereas Hypothesis 3 is not.

The theoretical contribution of this research is twofold. First, the findings of this study document a crucial contingent factor, consumer shopping purposes, for the effects of information control, suggesting that information control might meet the needs of utilitarian consumers more than those of hedonic consumers. Second, this contingent factor is fundamentally different from those in previous research. Thus far, the contingent factors investigated for the effects of information control, such as the need for cognition (Sicilia et al. 2005), expertise (Wu and Lin 2006), and motivation ( Wu and Lin 2012), relate to the cognitive capacity devoted by consumers in the process of product information seeking. By contrast, shopping purposes direct the goals and paths of information seeking by leading the direction of consumers' cognitive efforts. Utilitarian consumers have a specific shopping goal and adopt a directed search behavior, whereas hedonic consumers have no specific goals and conduct an exploratory search behavior. This research documents a fundamentally different type of contingent factor for the effects of information control, which can further support and expand the scope of the contingency view of information control.
Three managerial implications can be derived from this research. First, website designers could determine the appropriate level of information control for online consumers with different shopping purposes. Although shopping purposes are generally not explicitly expressed by consumers, they can be measured by collecting consumers' usage behaviors online through, for example, clickstream, pages viewed, and items purchased. Second, the findings of this study provide useful personalization strategies to advertisers who can offer product information to utilitarian and hedonic consumers via different levels of information control. Third, users benefit from information control differently when they have different shopping purposes. Websites offer relevant product information to users through the personalized features of information control, thereby ensuring that the task of information seeking can become more efficient and effective.

\subsection{Discussion}

Some empirical results in this study must be discussed further. Contrary to the hypotheses, no moderating effects on website satisfaction were observed. The possible explanation can be the higher levels of enjoyment in hedonic consumers (Babin and Darden 1996, Machleit and Mantel 2001), which may lead to a higher level of satisfaction. Hedonic consumers shop for enjoyment; therefore, they are likely to be in a good mood when browsing websites. Therefore, hedonic consumers also generate favorable attitudes toward websites, despite not needing the assistance of information control as much as utilitarian consumers do.

The empirical results also show that physical control and perceived control exert the same effects, suggesting that the manipulation of physical control in this study was successful at effectively incurring correspondent levels of perceived control, which mediates the effects of physical control on shopping experiences. Such findings indicate that the manipulation of physical control in this study can serve as a useful guideline for website operators designing different levels of information control for their websites.

\subsection{Limitations and future research}

There are some limitations in this study. First, we assigned the shopping purposes instead of allowing the participants to establish them. Such manipulation of shopping purposes may raise a concern about the robustness of the effects. Nonetheless, the results of the manipulation check suggest that the assigned shopping purposes can be successfully simulated in experimental labs. Moreover, the effects of manipulated shopping purposes should be weaker than those of their natural forms. Because the effects of manipulated shopping purposes are found, the effects of natural shopping purposes should be even stronger. Therefore, the robustness of the effects should not be a concern. Second, although some nonstudent samples were included in our experiment, the composite sample is still arguably student-saturated and not adequately representative. To examine the external validity of our research results, we conducted $\mathrm{K}-\mathrm{S}$ test analysis. The results reveal that there are no significant differences between students and nonstudents regarding their responses. Therefore, the concern about student samples should not severely affect the external validity of the results of this study. Nevertheless, this is still a substantial concern and a limitation of this research.

Several other concerns should be addressed in future research. First, Zhang (2008) argued that the design of affordances in information and communication technology (ICT) should support users' motivational needs such as those that are psychological, cognitive, social, and emotional. Thus, other motivational needs could be investigated to determine whether they also serve as crucial contingent factors for the effects of information control, and further 
consolidate the contingency view of information control. Second, this study examined the moderation effects of information control from the perspective of consumers. However, other situational factors, such as product type, website type, could also play a contingent role in the effects of information control and hence should also be investigated in future research. Third, information control could be explored in the context of online social interactions. Because of the growth of social network sites, online users disclose an increasing amount of private information in communication; hence, privacy has become paramount for online users. Social network sites may need to provide features of privacy control to help online users decrease their perceived risks. Privacy control, as a method for controlling how to share private information (Keith et al. 2014), can be deemed a form of information control. Hence, it will be beneficial to determine how the concept of information control can be used to account for privacy control in social network sites.

\section{Acknowledgement}

This research was partially supported by Ministry of Science and Technology of Taiwan for providing the research Grant (1012410-H-002-027-MY3).

\section{Appendix A. Measurement items and their sources}

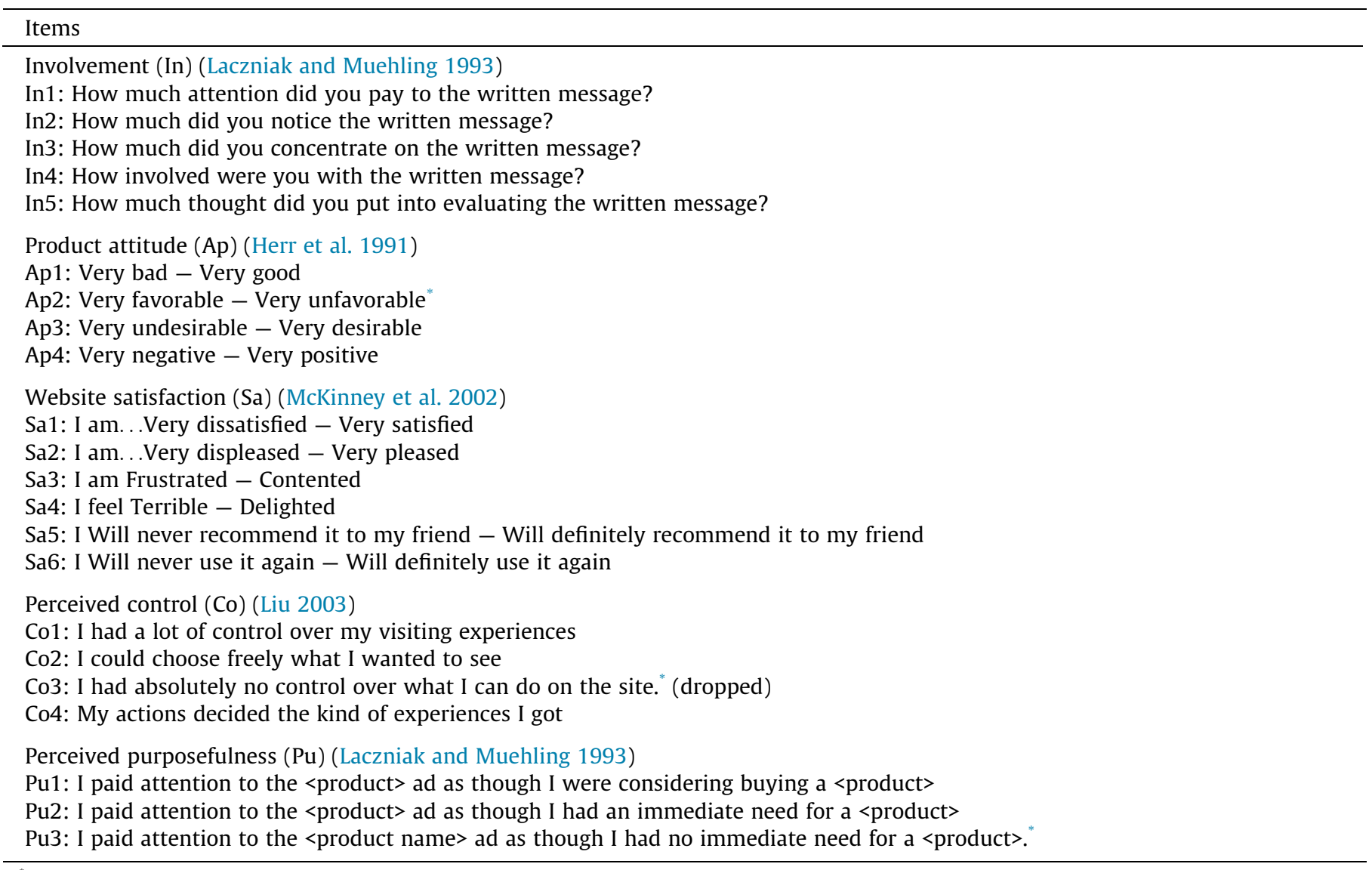

"Reverse item.

Appendix B. Descriptive statistics for each item: both groups combined, high control group, low control group, utilitarian group, and hedonic group

\begin{tabular}{|c|c|c|c|c|c|c|c|c|c|c|}
\hline \multirow[t]{2}{*}{ Items } & \multicolumn{2}{|c|}{$\begin{array}{l}\text { Both groups } \\
\text { combined } \\
(n=292) \\
\end{array}$} & \multicolumn{2}{|c|}{$\begin{array}{l}\text { High control } \\
\text { group }(n=144)\end{array}$} & \multicolumn{2}{|c|}{$\begin{array}{l}\text { Low control } \\
\text { group }(n=148)\end{array}$} & \multicolumn{2}{|c|}{$\begin{array}{l}\text { Utilitarian group } \\
(n=141)\end{array}$} & \multicolumn{2}{|c|}{$\begin{array}{l}\text { Hedonic group } \\
(n=151)\end{array}$} \\
\hline & Mean & SD & Mean & SD & Mean & SD & Mean & SD & Mean & SD \\
\hline In1 & 4.73 & 0.90 & 4.95 & 0.84 & 4.51 & 0.90 & 4.90 & 0.95 & 4.57 & 0.81 \\
\hline In 2 & 4.76 & 0.84 & 4.95 & 0.84 & 4.58 & 0.81 & 4.95 & 0.90 & 4.59 & 0.75 \\
\hline In3 & 4.67 & 0.90 & 4.91 & 0.86 & 4.44 & 0.88 & 4.87 & 0.95 & 4.49 & 0.82 \\
\hline
\end{tabular}


Appendix B (continued)

\begin{tabular}{|c|c|c|c|c|c|c|c|c|c|c|}
\hline \multirow[t]{2}{*}{ Items } & \multicolumn{2}{|c|}{$\begin{array}{l}\text { Both groups } \\
\text { combined } \\
(n=292)\end{array}$} & \multicolumn{2}{|c|}{$\begin{array}{l}\text { High control } \\
\text { group }(n=144)\end{array}$} & \multicolumn{2}{|c|}{$\begin{array}{l}\text { Low control } \\
\text { group }(n=148)\end{array}$} & \multicolumn{2}{|c|}{$\begin{array}{l}\text { Utilitarian group } \\
(n=141)\end{array}$} & \multicolumn{2}{|c|}{$\begin{array}{l}\text { Hedonic group } \\
(n=151)\end{array}$} \\
\hline & Mean & SD & Mean & SD & Mean & SD & Mean & SD & Mean & $\mathrm{SD}$ \\
\hline In4 & 4.66 & 0.86 & 4.90 & 0.82 & 4.43 & 0.84 & 4.86 & 0.91 & 4.48 & 0.78 \\
\hline $\operatorname{In} 5$ & 4.61 & 0.88 & 4.81 & 0.84 & 4.41 & 0.87 & 4.81 & 0.91 & 4.42 & 0.80 \\
\hline Ap1 & 4.59 & 0.72 & 4.79 & 0.73 & 4.40 & 0.67 & 4.74 & 0.79 & 4.45 & 0.63 \\
\hline Ap2 & 4.22 & 0.73 & 4.42 & 0.75 & 4.03 & 0.66 & 4.29 & 0.84 & 4.16 & 0.60 \\
\hline Ap3 & 4.29 & 0.83 & 4.52 & 0.81 & 4.07 & 0.80 & 4.51 & 0.87 & 4.09 & 0.75 \\
\hline Ap4 & 4.56 & 0.74 & 4.74 & 0.75 & 4.38 & 0.69 & 4.71 & 0.79 & 4.42 & 0.67 \\
\hline Sa1 & 4.47 & 0.86 & 4.76 & 0.93 & 4.19 & 0.68 & 4.66 & 0.90 & 4.30 & 0.79 \\
\hline Sa2 & 4.34 & 0.81 & 4.60 & 0.90 & 4.08 & 0.63 & 4.57 & 0.83 & 4.13 & 0.75 \\
\hline Sa3 & 4.45 & 0.80 & 4.70 & 0.89 & 4.21 & 0.61 & 4.63 & 0.85 & 4.29 & 0.71 \\
\hline Sa4 & 4.41 & 0.86 & 4.71 & 0.93 & 4.11 & 0.68 & 4.61 & 0.88 & 4.21 & 0.80 \\
\hline Sa5 & 4.22 & 1.13 & 4.66 & 1.09 & 3.79 & 1.01 & 4.51 & 1.07 & 3.95 & 1.13 \\
\hline Sa6 & 4.37 & 1.05 & 4.68 & 1.07 & 4.07 & 0.94 & 4.54 & 1.03 & 4.22 & 1.05 \\
\hline Co1 & 4.83 & 1.66 & 5.29 & 1.39 & 4.37 & 1.78 & 4.94 & 1.64 & 4.72 & 1.67 \\
\hline $\mathrm{Co} 2$ & 4.74 & 1.76 & 5.32 & 1.41 & 4.18 & 1.89 & 5.01 & 1.70 & 4.49 & 1.79 \\
\hline Co4 & 4.54 & 1.63 & 5.09 & 1.37 & 4.01 & 1.70 & 4.79 & 1.61 & 4.31 & 1.63 \\
\hline Pu1 & 4.81 & 1.42 & 5.10 & 1.18 & 4.53 & 1.57 & 5.13 & 1.23 & 4.50 & 1.52 \\
\hline $\mathrm{Pu} 2$ & 4.26 & 1.51 & 4.62 & 1.46 & 3.91 & 1.48 & 4.77 & 1.37 & 3.78 & 1.49 \\
\hline Pu3 & 3.70 & 1.67 & 4.26 & 1.67 & 3.14 & 1.49 & 4.10 & 1.63 & 3.32 & 1.64 \\
\hline
\end{tabular}

Note: In: involvement; Ap: product attitude; Sa: website satisfaction; Co: perceived control; Pu: perceived purposefulness.

\section{References}

Aiken, L.S., West, S.G., 1991. Multiple regression: testing and interpreting interactions. Sage, Newbury Park, CA.

Amichai-Hamburger, Y., Fine, A., Goldstein, A., 2004. The impact of Internet interactivity and need for closure on consumer preference. Comput. Hum. Behav. 20, 103-117.

Ariely, D., 2000. Controlling the information flow: effects on consumers' decision making and preferences. J. Consum. Res. 27, 233-248.

Babin, B.J., Darden, W.R., 1996. Good and bad shopping vibes: spending and patronage satisfaction. J. Bus. Res. 35, 201-206.

Babin, B.J., Darden, W.R., Griffin, M., 1994. Work and/or fun: measuring hedonic and utilitarian shopping value. J. Consum. Res. 20, 644-656.

Bateson, J.E.G., Hui, M.K.M., 1987. Perceived control as a crucial perceptual dimension of the service experience: an experimental study. In: Suprenant, C. F. (Ed.), Add Value to your Service. American Marketing Association, Chicago, pp. 187-192.

Batra, R., Ahtola, O.T., 1991. Measuring the hedonic and utilitarian sources of consumer attitudes. Marketing Lett. 2, 159-170.

Beatty, S.E., Smith, S.M., 1987. External search effort: an investigation across several product categories. J. Consum. Res. 14, 83-95.

Bellenger, D.N., Korgaonkar, P.K., 1980. Profiling the recreational shopper. J. Retail. 56, 77-92.

Bloch, P.H., Sherrell, D.L., Ridgway, N.M., 1986. Consumer search: an extended framework. J. Consum. Res. 13, 119-126.

Box, G.E., Cox, D.R., 1964. An analysis of transformations. J. Roy. Stat. Soc.: Ser. B (Methodol.), 211-252.

Bucy, E.P., Tao, C.-C., 2007. The mediated moderation model of interactivity. Media Psychol. 9, 647-672.

Carmines, E.G., Zeller, R.A., 1979. Reliability and Validity Assessment. Sage publications.

Chiou, J.S., Ting, C.C., 2011. Will you spend more money and time on internet shopping when the product and situation are right? Comput. Hum. Behav. 27 $203-208$.

Chung, H., Ahn, E., 2007. The effects of web site structure: the role of personal difference. Cyberpsychol. Behav. 10, 749-756.

Cohen, J., Cohen, P., West, S.G., Aiken, L.S., 2003. Applied multiple regression/correlation analysis for the behavioral sciences, third ed. L. Erlbaum Associates, Mahwah, N.J.

Collier, J.E., Sherrell, D.L., 2010. Examining the influence of control and convenience in a self-service setting. J. Acad. Mark. Sci. 38, 490-509.

Crutzen, R., Cyr, D., de Vries, N.K., 2012. The role of user control in adherence to and knowledge gained from a website: randomized comparison between a tunneled version and a freedom-of-choice version. J. Med. Internet Res. 14, e45.

Deci, E.L., Ryan, R.M., 1985. Intrinsic Motivation and Selfdetermination in Human Behavior. Plenum Press, New York.
Dhar, R., Wertenbroch, K., 2000. Consumer choice between hedonic and utilitarian goods. J. Mark. Res. 37, 60-71.

Diamantopoulos, A., Winklhofer, H.M., 2001. Index construction with formative indicators: an alternative to scale development. J. Mark. Res. 38, 269-277.

Epstein, S., 2003. Cognitive-experiential self-theory of personality. In: Theodore, M., Melvin, J., Lerner. (Eds.), Comprehensive Handbook of Psychology, vol. 5: Personality and Social Psychology, Wiley \& Sons; Hoboken, NJ, pp. 159-184.

Field, A., Miles, J., 2010. Discovering Statistics Using SAS. Sage, London.

Fornell, C., Larcker, D.F., 1981. Evaluating structural equation models with unobservable variables and measurement error. J. Mark. Res. 18, 39-50.

Fortin, D.R., Dholakia, R.R., 2005. Interactivity and vividness effects on socia presence and involvement with a web-based advertisement. J. Bus. Res. 58 387-396.

Furse, D.H., Punj, G.N., Stewart, D.W., 1984. A typology of individual search strategies among purchasers of new automobiles. J. Consum. Res. 10, 417-431.

Galbraith, J.R., 1973. Designing Complex Organizations. Addison-Wesley Longman Publishing Co. Inc., Boston, MA, USA.

Gefen, D., Straub, D., 2005. A practical guide to factorial validity using PLS-Graph: tutorial and annotated example. Commun. Assoc. Inf. Syst. 16, 91-109.

Gibson, J.J., 1987. The Ecological Approach to Visual Perception. Lawrence Erlbaum Associates, Mahwah, NJ.

Hair, J., Black, W., Babin, B., Anderson, R., 2010. Multivariate Data Analysis, seventh ed. Prentice Hall, Upper Saddle River, NJ.

Hair Jr., J.F., Hult, G.T.M., Ringle, C., Sarstedt, M., 2013. A Primer on Partial Least Squares Structural Equation Modeling (PLS-SEM). SAGE Publications Incorporated, Thousand Oaks.

Hauser, J.R., Urban, G.L., Weinberg, B.D., 1993. How consumers allocate their time when searching for information. J. Mark. Res. 30, 452-466.

Herr, P.M., Kardes, F.R., Kim, J., 1991. Effects of word-of-mouth and productattribute information on persuasion: an accessibility-diagnosticity perspective. J. Consum. Res. 17, 454-462.

Hirschman, E.C., Holbrook, M.B., 1982. Hedonic consumption: emerging concepts, methods and propositions. J. Marketing 46, 92-101.

Hoffman, D.L., Novak, T.P., 1996. Marketing in hypermedia computer-mediated environments: conceptual foundations. J. Marketing 60, 50-68.

Huang, E., 2012. Online experiences and virtual goods purchase intention. Internet Res. 22, 252-274.

Hulland, J., 1999. Use of partial least squares (PLS) in strategic management research: a review of four recent studies. Strateg. Manag. J. 20, 195-204.

Hwang, M.I., Lin, J.W., 1999. Information dimension, information overload and decision quality. J. Inf. Sci. 25, 213-218.

Hwang, J.S., McMillan, S.J., 2002. The role of interactivity and involvement in attitude toward the web site. In: Abernathy, A. (Ed.), Proceedings of the 2002 Conference of the American Academy of Advertising, Auburn University. Auburn, AL, pp. 10-17. 
Hwang, J.-S., McMillan, S.J., Lee, G., 2003. Corporate web sites as advertising: an analysis of function, audience, and message strategy. J. Interact. Advertising 3 , 10-23.

Insightxplorer, 2013. The demographic of online users.

Janiszewski, C., 1998. The influence of display characteristics on visual exploratory search behavior. J. Consum. Res. 25, 290-301.

Jarvenpaa, S.L., Todd, P.A., 1996. Consumer reactions to electronic shopping on the World Wide Web. Int. J. Electron. Commerce 1, 59-88.

Jiang, Z., Chan, J., Tan, B.C., Chua, W.S., 2010. Effects of interactivity on website involvement and purchase intention. J. Assoc. Inf. Syst. 11, 34-59.

Jones, M.A., Reynolds, K.E., Arnold, M.J., 2006. Hedonic and utilitarian shopping value: investigating differential effects on retail outcomes. J. Bus. Res. 59, 974981.

Kaltcheva, V.D., Weitz, B.A., 2006. When should a retailer create an exciting store environment? J. Marketing 70, 107-118.

Keith, M.J., Maynes, C., Lowry, P.B., Babb, J., 2014. Privacy fatigue: the effect of privacy control complexity on consumer electronic information disclosure. In: International Conference on Information Systems (ICIS 2014), Auckland, New Zealand.

Kim, K., Timm, N., 2007. Univariate and Multivariate General Linear Models: Theory and Applications with SAS, second ed. CRC Press, New York.

Kim, C., Galliers, R.D., Shin, N., Ryoo, J.-H., Kim, J., 2012. Factors influencing Interne shopping value and customer repurchase intention. Electron. Commer. Res. Appl. 11, 374-387.

Kleinmuntz, D.N., Schkade, D.A., 1993. Information displays and decision processes Psychol. Sci. 4, 221-227.

Laczniak, R.N., Muehling, D.D., 1993. The relationship between experimental manipulations and tests of theory in an advertising message involvement context. J. Advertising 22, 59-74.

Lee, T., 2005. The impact of perceptions of interactivity on customer trust and transaction intentions in mobile commerce. J. Electron. Commer. Res. 6, 165180.

Lee, S.-J., Lee, W.-N., Kim, H., Stout, P.A., 2004. A comparison of objective characteristics and user perception of web sites. J. Interact. Advertising 4, 6175.

Liu, Y., 2003. Developing a scale to measure the interactivity of websites. J. Advertising Res. 31, 207-216.

Liu, Y., Shrum, L., 2002. What is interactivity and is it always such a good thing? Implications of definition, person, and situation for the influence of interactivity on advertising effectiveness. J. Advertising 31, 53-64.

Machleit, K.A., Mantel, S.P., 2001. Emotional response and shopping satisfaction: moderating effects of shopper attributions. J. Bus. Res. 54, 97-106.

Martínez-López, F.J., Pla-García, C., Gázquez-Abad, J.C., Rodríguez-Ardura, I., 2014. Utilitarian motivations in online consumption: dimensional structure and scales. Electron. Commer. Res. Appl. 13, 188-204.

McKinney, V., Yoon, K., Zahedi, F., 2002. The measurement of web-customer satisfaction: an expectation and disconfirmation approach. Inf. Syst. Res. 13, 296-315.

McMillan, S.J., Hwang, J.-S., 2002. Measures of perceived interactivity: an exploration of the role of direction of communication, user control, and time in shaping perceptions of interactivity. J. Advertising 31, 29-42.
Moe, W.W., 2003. Buying, searching, or browsing: differentiating between online shoppers using in-store navigational clickstream. J. Consum. Psychol. 13, 29-39. Norman, D.A., 1999. Affordance, conventions, and design. Interactions 6, 38-43.

Novak, T.P., Hoffman, D.L., Duhachek, A., 2003. The influence of goal-directed and experiential activities on online flow experiences. J. Consum. Psychol. 13, 3-16.

Nunnally, J.C., 1978. Psychometric Theory, second ed. McGraw-Hill, New York.

Otley, D.T., 1980. The contingency theory of management accounting: achievement and prognosis. Acc. Organ. Soc. 5, 413-428.

Overby, J.W., Lee, E.-J., 2006. The effects of utilitarian and hedonic online shopping value on consumer preference and intentions. J. Bus. Res. 59, 1160-1166.

Pallant, J., 2010. SPSS Survival Manual: A Step by Step Guide to Data Analysis Using SPSS, fourth ed. Open University Press, Maidenhead, Berkshire.

Peterson, R.A., Balasubramanian, S., Bronnenberg, B.J., 1997. Exploring the implications of the Internet for consumer marketing. J. Acad. Mark. Sci. 25, 329-346.

Reinking, J., 2012. Contingency theory in information systems research. In: Dwivedi, Y.K., Wade, M.R., Schneberger, S.L. (Eds.), Information Systems Theory: Explaining and Predicting our Digital Society. Springer, New York, pp. 247-263.

Schkade, D.A., Kleinmuntz, D.N., 1994. Information displays and choice processes: differential effects of organization, form, and sequence. Organ. Behav. Hum. Decis. Process. 57, 319-337.

Sheth, J.N., 1983. An integrative theory of patronage preference and behavior. In: Darden, W.F., Lusch, R.F. (Eds.), Patronage Behavior and Retail Management. North-Holland, New York, pp. 9-28.

Sicilia, M., Ruiz, S., Munuera, J.L., 2005. Effects of interactivity in a web site: the moderating effect of need for cognition. J. Advertising 34, 31-44.

Song, J.H., Zinkhan, G.M., 2008. Determinants of perceived web site interactivity. J. Marketing 72, 99-113.

Stevens, J.P., 2012. Applied Multivariate Statistics for the Social Sciences. Routledge.

Teo, H.-H., Oh, L.-B., Liu, C., Wei, K.-K., 2003. An empirical study of the effects of interactivity on web user attitude. Int. J. Hum-Comput. St. 58, 281-305.

To, P.-L., Liao, C., Lin, T.-H., 2007. Shopping motivations on Internet: a study based on utilitarian and hedonic value. Technovation 27, 774-787.

Torenvliet, G., 2003. We can't afford it!: the devaluation of a usability term. Interactions 10, 12-17.

Tremayne, M., 2005. Lessons learned from experiments with interactivity on the Web. J. Interact. Advertising 5, 40-46.

Voorveld, H.A., Neijens, P.C., Smit, E.G., 2011. The relation between actual and perceived interactivity. J. Advertising 40, 77-92.

Weathers, D., Sharma, S., Wood, S.L., 2007. Effects of online communication practices on consumer perceptions of performance uncertainty for search and experience goods. J. Retail. 83, 393-401.

Wolfinbarger, M., Gilly, M.C., 2001. Shopping online for freedom, control, and fun. California Manage. Rev. 43, 34-55.

Wu, G., 2005. The mediating role of perceived interactivity in the effect of actual interactivity on attitude toward the website. J. Interact. Advertising 5, 29-39.

Wu, L.L., Lin, J.Y., 2006. The quality of consumers' decision-making in the environment of e-commerce. Psychol. Marketing 23, 297-311.

Wu, L.L., Lin, J.Y., 2012. The match between information control and motivation in the online context. Psychol. Marketing 29, 822-835.

Zhang, P., 2008. Technical opinion motivational affordances: reasons for ICT design and use. Commun. ACM 51, 145-147. 